\title{
Empresas e tecnologias na nova conjuntura vinícola brasileira do início do século XXI
}

\author{
Felipe Athia* \\ Armando Dalla Costa**
}

\begin{abstract}
RESUMO - A partir do final da década de 1980, o Brasil observou um acentuado crescimento em sua produção vitícola, em especial no Rio Grande do Sul. O estado, cuja produção corresponde a mais de $50 \%$ do total nacional, abriga as maiores produtoras do Brasil, com destaque para a Cooperativa Vinícola Aurora, Vinícola Serra Gaúcha e Vinhos Salton, todas concentradas na região das Serras Gaúchas. O propósito do presente trabalho é analisar o panorama da vitivinicultura brasileira, com destaque para o estado do Rio Grande do Sul, explicitando as estratégias de crescimento utilizadas pelas dez maiores empresas do ramo.
\end{abstract}

Palavras-chave: Vinho. Vitivinicultura brasileira. Conglomerados industriais. Teoria do crescimento da firma. Cooperativas agrícolas. Empresas familiares.

\section{INTRODUÇÃO}

A vitivinicultura no Brasil tem evoluído de maneira significativa a partir do final da década de 1980. Embora o país não possa ser considerado - ainda - um produtor de escala mundial, a produção e a qualidade dos produtos têm aumentado consideravelmente nos últimos anos, principalmente após a entrada do Brasil na OIV (Office International de la Vigne et $d u$ Vin, em português "Organização Internacional do Vinho"), que promoveu um aumento nos padrões de qualidade.

O crescimento deste mercado enfrenta dois problemas principais, a saber: a baixa demanda interna e os elevados preços do produto nacional. Acredita-se, atualmente, que essa baixa demanda é um resultado direto do baixo poder aquisitivo da população brasileira e, sobretudo, da falta de tradição no consumo do vinho por parte das famílias. A partir da virada do milênio essa atividade tem apresentado crescimentos regulares, tanto nos produtos

\footnotetext{
* Estudante de Economia da Universidade Federal do Paraná (UFPR) e estagiário do Instituto Paranaense de Desenvolvimento Econômico e Social (IPARDES).

** Pós Doutor pela Université de Picardie Jules Verne, Amiens, França e Doutor pela Université de Paris III (Sorbonne Nouvelle). Professor no Departamento de Economia e no Programa de Pós-Graduação em Desenvolvimento Econômico da UFPR. Coordenador do Núcleo de Pesquisa em Economia Empresarial. Endereço eletrônico: ajdcosta@ufpr.br.
} 
elaborados como na produção de uva para consumo in natura. Em 2006, foram produzidas cerca de 1,22 milhão de toneladas de uva; em 2007, a produção atingiu mais de 1,35 milhão, aumento de cerca de 11\%. Desse total, $47 \%$ foram destinados à produção de vinhos e sucos (IBGE, 2007a).

A principal parcela da produção brasileira se encontra no Rio Grande do Sul, com destaque para a região norte, nas Serras Gaúchas. O estado concentra cerca de $52 \%$ da produção brasileira possuindo, além disso, as consideradas melhores vinícolas do país, nas cidades de Bento Gonçalves, Garibaldi e Caxias do Sul, além de Flores da Cunha, Farroupilha, Canela e Erechim (MELLO, 2008). O estado abriga a ABE (Associação Brasileira de Enologia), a UVIBRA (União Brasileira de Vitivinicultura), a EMBRAPA Uvas e Vinho, que se dedicam ao controle de qualidade e pesquisa na área; e a Escola Agrotécnica Federal Presidente Juscelino Kubitschek, em Bento Gonçalves que, a partir de 1995, passou a ofertar o Curso Superior de Tecnologia em Viticultura e Enologia, o primeiro centro voltado para a formação de enólogos do Brasil e um dos poucos da América Latina.

Embora o extremo sul do estado possua produção considerável, na região de Santana do Livramento (Viamão e Campanha), a região das Serras Gaúchas é, sem dúvida, o "pulmão" da vitivinicultura brasileira; possui cerca de 300 vinícolas e condições geoclimáticas relativamente próximas às dos países vinícolas da Europa. Grande parte das vinícolas dessa região utiliza cepas nobres ${ }^{1}$ e se alicerça em alta tecnologia, utilizando padrões de produção semelhantes aos implantados na França, Itália, Portugal e Espanha, os principais produtores mundiais. Dentre as 10 maiores empresas do ramo no país - Cooperativa Vinícola Aurora, Vinícola Serra Gaúcha, Vinhos Salton, Cooperativa Vinícola São João, Sociedade de Bebidas Panizzon, Antônio Basso \& Filhos, Cantina da Serra, Cooperativa Vinícola Garibaldi, Vinícola Perini e Catafesta Indústria de Vinhos - todas se encontram no Rio Grande do Sul, na região das Serras Gaúchas e em seus arredores.

O objetivo deste trabalho é analisar o panorama e as principais perspectivas da vitivinicultura brasileira, com destaque para o estado do Rio Grande do Sul, explicitando as estratégias de crescimento utilizadas e seus respectivos impactos na produtividade das maiores empresas do ramo.

\footnotetext{
1 As cepas são variedades de uvas com características próprias como, por exemplo, a cor, o tamanho das bagas, a sua resistência às pragas, a produtividade, a adaptação à terra onde vai ser cultivada, etc. As denominadas "cepas nobres" são: Cabernet Sauvignon, Merlot, Shiraz, Pinotage, Sauvignon Blanc, Chardonnay.
} 


\section{A VITIVINICULTURA NO BRASIL: UM PANORAMA}

\subsection{RIO GRANDE DO SUL: O MOTOR DA VITIVINICULTURA BRASILEIRA}

Embora a cidade de São Paulo tenha sido o primeiro centro vitícola brasileiro, a vitivinicultura brasileira se desenvolveu inicialmente no Rio Grande do Sul devido, principalmente à massiva imigração europeia no final do século XIX, por volta de 1875, aliada ao clima diferenciado. Segundo Flores et al..(2007), o clima é determinante no potencial vitícola das regiões, visto que o mesmo manifesta sua influência através de diversos elementos, entre os quais destacam-se a temperatura, a insolação e as precipitações. A tabela 1 mostra que mais de $50 \%$ das áreas da região das Serras Gaúchas é preferencial ou recomendável ao cultivo das parreiras, índice muito mais elevado que em outras regiões do país.

TABELA 1 - SUPERFÍCIES DAS CLASSES DE POTENCIAL EDÁFICO PARA A VITIVINICULTURA NAS SERRAS GAÚCHAS ${ }^{2}$

\begin{tabular}{l|r|r}
\hline \multicolumn{1}{c|}{ Classe de potencial edáfico } & Área (ha) & \multicolumn{1}{c}{ Área(\%) } \\
\hline Preferencial & $464.259,34$ & 34,42 \\
Recomendável & $311.511,35$ & 23,09 \\
Pouco recomendável & $24.209,74$ & 1,79 \\
Não recomendável & $548.980,88$ & 40,70 \\
Total & $1.348 .961,31$ & 100,00 \\
\hline
\end{tabular}

FONTE: FLORES et al.(2007).

Dessa forma, por possuir clima favorável e mão-de-obra relativamente qualificada muitos imigrantes italianos vieram da região da Toscana e Sicília, duas das principais regiões produtoras da Itália - a região observou rápido crescimento da atividade tornando-se, com maior intensidade a partir de 1960-70, uma das mais importantes atividades econômicas do estado.

Entretanto, foi a partir da segunda metade da década de 1990 que se iniciou um processo visando o melhoramento técnico da produção. Segundo o IBRAVIN (Instituto Brasileiro do Vinho) o setor possuía, em 2003, 617 indústrias voltadas para a produção do vinho, distribuídas entre empresas de pequeno, médio e grande porte nos 45 municípios do estado. A atividade exerce, ainda, um papel de cunho social muito importante visto que mobiliza cerca de 13 mil famílias na produção da matéria-prima.

\footnotetext{
${ }^{2}$ Em suma, a análise realizada por FLORES et al.(2007) incorporou diversos elementos que fariam determinada região ser considerada preferencial, recomendável, pouco recomendável ou não recomendável para a produção de vinhos, a saber: solo (textura, profundidade, espessura e teor de matéria orgânica do horizonte A e drenagem), relevo, temperatura, pedregosidade e umidade.
} 
Tonietto (2003) divide a atividade em quatro períodos, a saber: implantação da vitivinicultura; segundo período evolutivo; terceiro período evolutivo; e quarto período evolutivo.

O período relacionado à implantação da atividade, para o autor, se iniciou com a chegada dos primeiros imigrantes italianos e durou até 1929. Nesta fase poucos avanços foram feitos, com destaque para a importação de cepas italianas visando o melhoramento dos vinhos aqui produzidos, com subsídio da Estação Agronômica de Porto Alegre (1910) e a criação da Estação Experimental de Viticultura e Enologia em Caixas do Sul (1920), pertencente ao Ministério da Agricultura. Segundo Angheben ${ }^{3}$ (apud SOUZA, 2005), em entrevista sobre o tema a baixa qualidade dos produtos era devida, principalmente, às variedades cultivadas e ao baixo conhecimento técnico empregado em sua elaboração.

O segundo período evolutivo está compreendido entre as décadas de 1930 e 1960 com destaque especial para o surgimento das cooperativas, algumas das quais perduram até hoje e são as maiores empresas do segmento no país. A produção aumentou consideravelmente para atender outros mercados e em 1936 foi criado o Instituto RioGrandense do Vinho. Com o crescimento do mercado e da demanda por melhoramentos na produção foi criada, em 1959, a Escola de Viticultura e Enologia (atual CEFET-BG).

O terceiro período evolutivo, iniciado em 1970 e com fim em meados da década de 1990, caracterizou-se por investimentos e empreendimentos estrangeiros no país, mudanças das cepas utilizadas na produção e investimentos governamentais no segmento como, por exemplo, a criação, em 1975, da Embrapa Uva e Vinho em Bento Gonçalves-RS, além de significativo aumento da área cultivada. Com a abertura comercial do país no período a preferência do consumidor por vinhos estrangeiros - ainda com preços relativamente menores que os nacionais - aumentou, fazendo com que para se manterem no mercado de forma competitiva as indústrias nacionais tivessem que buscar inovações tecnológicas visando a satisfação das exigências dos consumidores.

O quarto e último período evolutivo emergiu, de certa forma, como consequência da abertura comercial brasileira com início em 2000 e duração até os dias atuais. Neste período ocorreu o investimento em mão-de-obra qualificada e aprendizado "in loco", isto é, o envio de funcionários para países como a França, Itália e Portugal, visando o aprendizado de novas técnicas. Segundo Souza (2005) um fator essencial para a melhoria das condições da atividade no período foi a criação do Curso Superior de Tecnologia em Viticultura e Enologia, em

\footnotetext{
${ }^{3}$ Professor de Viticultura do Centro Federal de Educação Tecnológica de Bento Gonçalves-RS.
} 
1995. Com a conclusão dos estudos em 1998 os recém-formados puderam atuar em áreas antes não exploradas em empresas de menor porte como, por exemplo, planejamento estratégico e marketing "proporcionando o surgimento de pequenas empresas vinícolas" (SOUZA, 2005).

Da produção nacional, que atingiu 1,39 milhão de toneladas de uva em $2008^{4}$, o estado é responsável por 55\%, isto é, cerca de 780 mil toneladas, $10 \%$ acima dos números apresentados em 2007. Segundo Mello (2009), a parcela da produção gaúcha destinada ao processamento (produção de vinhos, sucos e derivados), pela primeira vez ultrapassa a parcela destinada ao consumo in natura; a primeira cresceu 11\% de 2007 para 2008, enquanto a segunda caiu cerca de 4\%, ficando evidente o aumento da importância da atividade no estado. Em todos os outros estados, segundo a autora, o consumo in natura é maior que o consumo industrial da fruta.

GRÁFICO 1 - EVOLUÇÂO DA PRODUÇÂO DE UVA NO BRASIL NO PERÍODO 1975-2008

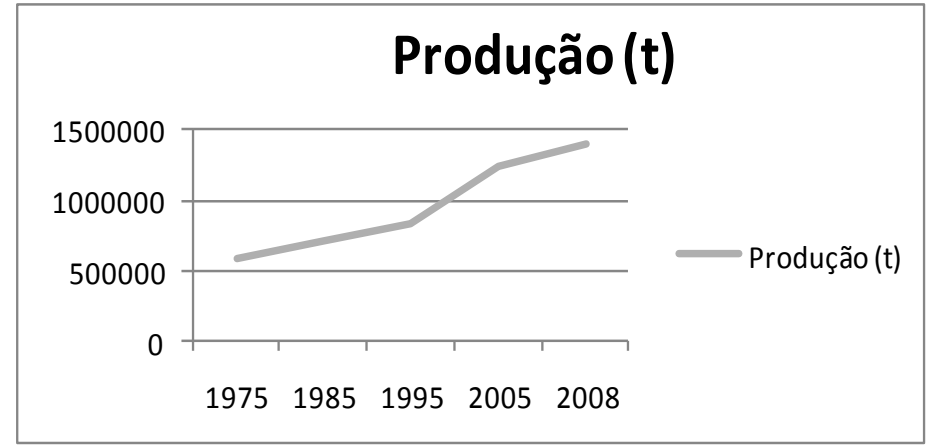

FONTE: Elaboração dos autores a partir dos dados de MELLO et al. 2007, IBGE, 2007b e MELLO, 2009.

\subsection{OUTRAS REGIÕES PRODUTORAS}

Além do Rio Grande do Sul, uma considerável parcela dos vinhos brasileiros é produzida no Vale do Rio São Francisco, especialmente na cidade de Santa Maria da Boa Vista, próxima de Petrolina e Juazeiro, na fronteira dos estados de Pernambuco e Bahia. A região se destaca como um dos maiores produtores de vinho do mundo, sendo a única no Brasil a atingir a marca de duas safras e meia por ano, mantendo uma média de produção anual de 20,5 mil toneladas de uva e sete milhões de litros de vinho. Produz boa parte dos vinhos de mesa brasileiros e também se destaca pela produção de vinhos de origem europeia, como o Cabernet Sawignon e o Chenin Blanc (SILVA, 2008).

\footnotetext{
${ }^{4}$ Os dados referentes ao ano de 2008 são estimativas de MELLO (2009). A autora é pesquisadora-chefe da EMBRAPA Uva e Vinho.
} 
O restante da produção nacional é proveniente de regiões vitícolas situadas nos estados de Minas Gerais (municípios de Andradas, Caldas, Poços de Caldas e Santa Rita de Caldas), Paraná, Santa Catarina (Urussanga) e São Paulo (Jundiaí e São Roque). No entanto essas regiões cultivam, em sua maioria, uvas americanas (Isabel, Niágara, etc.) que originam apenas vinhos de categoria inferior.

Dentre as acima mencionadas a que aparentemente vem apresentando crescimento mais significativo é o estado do Paraná, cuja produção era de cerca de 43 mil toneladas e área plantada 3,6 mil hectares em 1994. Pouco mais de dez anos depois, em 2007, a produção atingiu cerca de 100 mil toneladas, representando um crescimento de $132 \%$ e área cultivada de 5,7 mil hectares, com crescimento de 58\%. Esses números embora relativamente pequenos se comparados aos grandes produtores brasileiros - Rio Grande do Sul e Região Nordeste -, vêm aumentando e acredita-se que o estado esteja desenvolvendo um potencial considerável para a vitivinicultura, com destaque para o município de Marialva, próximo a Maringá que, com pouco mais de 30 mil habitantes é responsável por $50 \%$ da produção paranaense. Ocupando 1,7 mil hectares (cerca de 30\% da área cultivada no Paraná) e gerando 7 mil empregos diretos e indiretos, a produção atingiu em 2007, 51 mil toneladas (PARANÁ ONLINE, 2009). A evolução das diversas regiões e estados do país pode ser acompanhada analisando-se os dados da tabela 2.

Apesar de quase todos os Estados apresentarem alguma produção, a vitivinicultura vem se desenvolvendo nas regiões tradicionais, com uma entrada forte da Bahia, a partir de meados dos anos 1990. Os cinco maiores estados produtores são responsáveis pela maior parte da produção, como se pode observar pela Tabela 3.

\section{AS PRINCIPAIS EMPRESAS PRODUTORAS E SUAS ESTRATÉGIAS}

A agroindústria do vinho nacional, centrada desde seus primórdios no Rio Grande do Sul, pôde observar, em especial a partir da década de 1990, investimentos relacionados à implantação e/ou modernização das vinícolas, alicerçadas em um mercado interno com potencial para produtos de melhor qualidade (vinhos finos) e de maior preço. Desde então se verificou um intenso e "exponencial" processo de modernização tecnológica das vinícolas e processadoras de suco de uva. O nível tecnológico utilizado no processo de elaboração dos vinhos finos pelo setor agroindustrial nacional é comparável àquele existente nos países de vitivinicultura avançada, embora essa evolução não esteja presente na elaboração de vinhos de mesa (PROTAS et al. 2002). 
TABELA 2 - BRASIL - EVOLUÇÃO DA ÁREA PLANTADA NOS ESTADOS - 1975-2003 (EM HA)

\begin{tabular}{lrrrrrrrrrr}
\hline UF & \multicolumn{2}{c}{1975} & \multicolumn{2}{c}{1985} & \multicolumn{2}{c|}{1995} & \multicolumn{2}{|c}{2003} \\
\hline & Área & $\%$ & Área & $\%$ & Área & $\%$ & Área & $\%$ \\
RO & 0 & 0,00 & 0 & 0,00 & 0 & 0,00 & 32 & 0,05 \\
TO & 0 & 0,00 & 0 & 0,00 & 0 & 0,00 & 6 & 0,01 \\
PI & 0 & 0,00 & 0 & 0,00 & 1 & 0,00 & 4 & 0,01 \\
CE & 4 & 0,01 & 4 & 0,01 & 12 & 0,02 & 49 & 0,07 \\
RN & 0 & 0,00 & 0 & 0,00 & 67 & 0,11 & 0 & 0,00 \\
PB & 127 & 0,22 & 71 & 0,12 & 100 & 0,16 & 80 & 0,15 \\
PE & 358 & 0,62 & 730 & 1,26 & 2.615 & 4,30 & 3.423 & 5,00 \\
SE & 0 & 0,00 & 0 & 0,00 & 1 & 0,00 & 0 & 0,00 \\
BA & 38 & 0,07 & 159 & 0,27 & 2.042 & 3,36 & 3.356 & 4,90 \\
MG & 1.335 & 2,31 & 924 & 1,60 & 835 & 1,37 & 907 & 1,33 \\
ES & 53 & 0,09 & 55 & 0,10 & 17 & 0,03 & 21 & 0,03 \\
RJ & 12 & 0,02 & 28 & 0,05 & 0 & 0,00 & 0 & 0,00 \\
SP & 9.889 & 17,14 & 8.671 & 14,99 & 9.519 & 15,65 & 12.395 & 18,11 \\
PR & 2.390 & 4,14 & 2.234 & 3,86 & 3.845 & 6,32 & 5.652 & 8,26 \\
SC & 4.500 & 7,80 & 5.769 & 9,97 & 3.734 & 6,14 & 3.671 & 5,36 \\
RS & 39.000 & 67,58 & 39.207 & 67,77 & 38.008 & 62,50 & 38.517 & 56,29 \\
MS & 3 & 0,01 & 0 & 0,00 & 5 & 0,01 & 79 & 0,12 \\
MT & 0 & 0,00 & 0 & 0,00 & 7 & 0,01 & 219 & 0,32 \\
GO & 0 & 0,00 & 0 & 0,00 & 0 & 0,00 & 20 & 0,03 \\
DF & 0 & 0,00 & 0 & 0,00 & 2 & 0,00 & 1 & 0,00 \\
BR & 57.709 & 100,00 & 57.852 & 100,00 & 60.810 & 100,00 & 68.432 & 100,00 \\
\hline
\end{tabular}

FONTE: MELLO et al. 2007.

TABELA 3 - PRODUÇÃO DOS 5 MAIORES ESTADOS PRODUTORES EM 2007

\begin{tabular}{l|r}
\multicolumn{1}{c|}{ Estado } & \multicolumn{1}{c}{ Produção (t) } \\
\hline Rio Grande do Sul & 704176 \\
São Paulo & 198123 \\
Pernambuco & 170325 \\
Bahia & 119610 \\
Paraná & 99180 \\
TOTAL BRASIL & 1371555 \\
\hline
\end{tabular}

FONTE: Elaboração dos autores a partir dos dados de IBGE, 2007b.

A inserção de novas tecnologias, mão-de-obra especializada e investimentos não só nas máquinas e equipamentos, mas também nas sementes, têm promovido, cada vez mais, os vinhos da Serra Gaúcha a nível internacional. Segundo os dados da ABE (2004, apud SOUZA, 2005) $)^{5}$ os vinhos gaúchos ganharam em 2003 cerca de 900 prêmios em concursos realizados em países como França, Itália, Espanha, Portugal, Bélgica, Inglaterra, China e Argentina, dentre outros.

Entre os prêmios a maior parte foi recebida por produtos provenientes das maiores vinícolas do país que, de modo geral, se localizam na região das Serras Gaúchas. As maiores empresas, em ordem decrescente de produção são, segundo Bottega (2009), Cooperativa Vinícola Aurora, Vinícola Serra Gaúcha, Vinhos Salton, Cooperativa Vinícola São João,

${ }^{5}$ Associação Brasileira de Enologia. Dados Estatísticos, 2004. 
Sociedade de Bebidas Panizzon, Antônio Basso \& Filhos, Cantina da Serra, Cooperativa Vinícola Garibaldi, Vinícola Perini e Catafesta Indústria de Vinhos.

A inovação - embora já tivesse sido abordada de modo superficial anteriormente - ganha espaço na teoria econômica a partir das ideias de Schumpeter (1985). Segundo este autor, a inovação seria um processo caracterizado pela mudança dos paradigmas já existentes, isto é, a descontinuidade do que está estabelecido. Neste sentido, verifica-se que, nas já citadas maiores empresas do ramo, a inovação teve participação essencial no que tange os processos produtivos e a distribuição dos produtos, enquanto a gestão das empresas sofreu mudanças de menores magnitudes apenas. Além disso, vale ressaltar o esforço de algumas empresas na criação de novos produtos, isto é, a tentativa - na maioria das vezes bem sucedida - de introduzir vinhos produzidos através de cepas anteriormente inutilizadas ou, ainda, desenvolver novos vinhos equilibrando diferentes cepas tentando, assim, atingir mercados menos explorados e com demanda crescente.

Em linhas gerais, em relação aos processos de produção, as principais áreas afetadas condizem com o manejo do solo e das plantas; mudanças no sistema de reconversão dos vinhedos; alterações no recebimento e desengace das uvas; controles especiais na fermentação e maceração; mudança nos locais de engarrafamento; e instalação de controles de rastreabilidade das uvas, dentre outros.

Por outro lado, as mudanças condizentes com a distribuição dos produtos, são encontradas em um número menor de empresas. A ampliação dos mercados interno e externo; mudanças na apresentação dos produtos; introdução dos produtos em estabelecimentos de qualidade superior; aliados com controles administrativos anteriormente inexistentes no que tange o sistema de gestão das empresas, foram cruciais para o desenvolvimento da atividade.

\section{CONCLUSÃO}

A vitivinicultura é uma atividade em plena expansão no Brasil e é responsável por uma fatia considerável da parcela do PIB relacionada à fruticultura. Presente em diversas áreas do território nacional, com destaque para o Rio Grande do Sul (Serras Gaúchas), Pernambuco e Bahia (Vale do Rio São Francisco), São Paulo (Região Metropolitana de Jundiaî) e Paraná (Norte, Sudoeste e Região Metropolitana de Curitiba), a atividade tem se mostrado uma alternativa de geração de renda e de melhoria da qualidade de vida para pequenos produtores rurais. 
Beneficiado pelo clima favorável e pela imigração italiana em larga escala a partir do final do século XIX, o estado do Rio Grande do Sul despontou como principal produtor nacional, sempre representando mais de $50 \%$ do total da produção, embora este percentual venha caindo ao longo dos anos. Essa diminuição percentual, não está relacionada com uma diminuição na produção gaúcha, mas sim com o aumento produtivo dos outros estados, em especial os já mencionados na Tabela 3. Em 2007, de 1,35 milhão de toneladas de uva produzidos no país, o estado é responsável por mais de 700 mil.

De modo geral, até meados da década de 1990, as vinícolas brasileiras se alicerçavam em baixa tecnologia e conhecimento técnico limitado para a elaboração de vinhos. Por volta de 2000, houve uma inversão neste cenário: as vinícolas iniciaram um processo de transformação, tornando-se verdadeiros conglomerados industriais. Houve mudanças ao longo de todo o processo, iniciando-se com a introdução de diferentes produtos, voltados para diversos públicos e mercados; foram feitos ajustes também nos processos e nas formas de distribuição dos produtos. Essas transformações, combinadas com a melhora no conhecimento técnico dos funcionários possibilitado, principalmente, por órgãos como a Embrapa Uva e Vinho, CEFET-BG, dentre outros e o sistema de aprendizagem "in loco" possibilitaram rápida expansão da atividade.

Embora a vitivinicultura seja um mercado com elevado potencial de crescimento, enfrenta alguns obstáculos. Acredita-se que os principais, além dos já mencionados, são o câmbio e a tributação, que influenciam a preferência do consumidor. No que se refere ao primeiro, a recente "re-valorização" do real tem incentivado o consumo de vinhos chilenos e argentinos. Já a tributação eleva o preço dos nacionais, independentemente da relação com os importados. Apesar desses obstáculos, a venda de vinhos nacionais apresentou crescimento de 12,7\% no primeiro quadrimestre de 2009 em relação ao mesmo período do ano anterior, enquanto o avanço dos importados não chegou a 3\% (VALOR ECONÔMICO, 2009).

\section{REFERÊNCIAS}

BOTTEGA, L. Dados fornecidos aos autores por mensagem eletrônica. Endereço eletrônico: estatistica@ibravin.org.br. Curitiba, 2 de junho de 2009.

CONGRESSO LATINOAMERICANO DE VITICULTURA E ENOLO0GIA, 11º 2007. Potencial edáfico da Serra Gaúcha, Brasil para Viticultura.

IBGE - INSTITUTO BRASILEIRO DE GEOGRAFIA E ESTATÍSTICA(2007a). Produção e Comercialização de Uvas e Vinhos: Panorama 2007. 
IBGE - INSTITUTO BRASILEIRO DE GEOGRAFIA E ESTATÍSTICA (2007b). Produção Agrícola Municipal 2007.

MELLO, L.M.R. Vitivinicultura Brasileira: Panorama 2007. Bento Gonçalves: EMBRAPA Uva e Vinho, 2008.

MELLO, L.M.R. Vitivinicultura Brasileira: Panorama 2008. Bento Gonçalves: EMBRAPA Uva e Vinho, 2009.

MELLO, L.M.R. et al. Evolução e Dinâmica da Produção de Uva no Brasil no Período 1975-2003. Bento Gonçalves: EMBRAPA Uva e Vinho, Documentos 62, 2007.

FLÁVIO LAGINSKI. Vinicultura ganha incentivo para crescer no estado. Paraná Online, Curitiba,01/fev/2009. Disponível em http://www.paranaonline.com.br/editoria/economia/news/351849/. Acesso em 16/04/2009.

SIMPÓSIO MINEIRO DE VITICULTURA E ENOLOGIA, 2002, Andradas-MG. A vitivinicultura brasileira: realidade e perspectivas.

SCHUMPETER, J. A Teoria do Desenvolvimento Econômico. São Paulo: Abril Cultural, 1985.

SILVA, M.S. O Panorama da Produção de Vinho no Brasil. Revista Ciência em Curso, Vol.3, n³, jul/set, 2008.

SOUZA, F.A. Mudanças Promovidas no Setor Vitivinícola do Rio Grande do Sul Pela Inserção de Profissionais Especializados nas Áreas de Viticultura e Enologia. 159 páginas, Dissertação de Mestrado em Educação Profissional Agrícola, Políticas Públicas e Gestão em Educação Profissional - UFRRJ, Rio de Janeiro, 2005.

TONIETTO, J. Vinhos brasileiros da $4^{\mathbf{a}}$ geração. Bento Gonçalves: EMBRAPA Uva e Vinho, Comunicado Técnico, 2003.

SÉRGIO BUENO. Vinícolas vendem até 30\% mais de janeiro a abril, Valor econômico. 26 de maio de 2009, p. B4, Caderno: Empresas/Tendências \& Consumo. 